\title{
JOB INSECURITY AND EMOTIONAL DISTURBANCE OF POLISH EMPLOYEES DURING PANDEMIC COVID-19
}

\author{
Teresa Chirkowska-Smolak, Mykola Chumak \\ Adam Mickiewicz University, Poznań, Poland \\ Faculty of Psychology and Cognitive Science
}

\begin{abstract}
Background: The pandemic, as an event that is new and dangerous to the health and life of the population, has put employees at risk of losing their job and experiencing deteriorating working and employment conditions. In this situation, authors were particularly concerned with the extent to which job insecurity (both quantitative and qualitative) contributed to the deterioration of workers' well-being. Material and Methods: The study was carried out on 382 Polish employees in April and May 2020. The following research tools were used: the Job Insecurity in Pandemic Scale by Chirkowska-Smolak and Czumak and the Depression, Anxiety, Stress Scale (DASS-21) by Levibond and Levibond. Results: The quantitative and qualitative job insecurity were significant predictors of depression and stress, but they did not explain anxiety symptoms. The scope of the explained variance of these negative emotional states by concerns related to work and employment was not large (from 11\% to $17.6 \%$ ). The moderating role of perceived employability was confirmed only in the case of the relationship between qualitative job insecurity and depression, as well as quantitative job insecurity and stress. However, the increase in the explained variance was very small. Conclusions: Uncertainty related to the maintenance of employment and concerns about the deterioration of working conditions due to the COVID-19 pandemic had an impact on emotional disturbances of employees, but they only explained some of the variance of depression and stress and did not affect the perceived level of anxiety. The smaller role of economic stress in the emergence of negative emotional states could be associated with the occurrence of much more serious threats to the health and life of the population in this period. The very low level of unemployment in Poland, which remained at a similar level throughout the pandemic despite the catastrophic forecasts of economists, could also have played an important role. Med Pr. 2021;72(6):645-52
\end{abstract}

Key words: depression, anxiety, stress, employability, job insecurity, COVID-19

Corresponding author: Teresa Chirkowska-Smolak, Adam Mickiewicz University, Faculty of Psychology and Cognitive Science, Szamarzewskiego 89,60-568 Poznań, Poland, e-mail: chirko@amu.edu.pl

Received: July 15, 2021, accepted: November 4, 2021

\section{INTRODUCTION}

The COVID-19 pandemic has changed the way many people live and work. It also has had a considerable impact on people's physical and mental health. Researchers, at first mostly interested in pandemic-related risk factors, have recently begun to pay more attention to economic factors and the indirect effect the pandemic has had on the economy via, e.g., deteriorating working conditions and increasing unemployment in a number of countries [1].

The changes that have had an effect on the population's mental health were sudden and have permeated various aspects of everyday life. This is why the pandemic ought to be looked at from a broader perspective. Clearly, one of its most important consequences was economic stress. Research from different countries around the world shows, among other things, that individuals with lower socio-economic status are hit harder by the consequences of the pandemic (higher infection rates), due to the limited capacity for remote work and a sense of lack of job security [2]. Particularly in the first phase of the pandemic, many employees felt more exposed to the virus in their workplace (considered main COVID-19 hotspots). At the same time, however, they were unable to quit their jobs in order to avoid the risk [3]. A share of people who lost their jobs around that time didn't actively seek employment on account of mounting epidemiological restrictions. As a result of the employment, economic and financial insecurity pervading the society, young people (who had never undertaken psychiatric treatment before) began experiencing sleeping disorders, anxiety disorders and depressive disorders.

Employees were also hit by adversities of another kind - deteriorating labor conditions, pay cuts, limited development and promotion opportunities - all consequences of cost reduction by organizations desperate to stay afloat. Measures taken by organizations with the aim to avoid the spreading of the virus 
in the workplace, such as remote work, have abruptly (and, in all likelihood, permanently) changed the way authors work [4]. Therefore, the anxiety related not only to the loss of employment, but the loss of work as authors had known it until now.

Thus, authors can talk about a mediating effect of economic threat between the occurrence of risk factors and mental health and wellbeing, since economic threat is related to the loss of resources important in dealing with stress and the perception of risk in larger threat categories [1].

A new and dangerous phenomenon, the pandemic meant organizations faced a crisis which they often couldn't deal with effectively. With insufficient backing from the state, struggling with the sanitary regime and lockdowns, a share of employers was forced to reduce workforce and, in some cases, even declare bankruptcy. This applied to entire industries, such as the aviation sector, gastronomy, hospitality or transportation. One of the characteristics of a crisis is that people (as well as organizations) have no ready-made modus operandi in a given situation, while the hitherto existing solutions become ineffective. Procedures elaborated by organizations were no longer adequate due to the dynamically changing situation. The future became more and more unpredictable (it wasn't clear how long the virus would persist) and crisis scenarios were increasingly difficult to draw up. Such situations are an ideal breeding ground for feelings of fear, uncertainty, unpredictability, anxiety and even panic. Uncertainty is an unpleasant affective state, experienced by an individual as discomfort, a sense of concern or anxiety [5]. When not neutralized right away, too high a level of anxiety could lead to a reduced psychological well-being, as it relates to extremely important values: life, health and economic security.

More and more studies conducted around the world indicated an increasing prevalence of mental disorders, such as anxiety, depression or stress [6-8] including among healthy people who had never undertaken psychiatric treatment before. As pointed out many years ago by Goldberg and Lecrubier [9], who investigated the frequency of psychological problems seen in primary health care around the world, depression and anxiety are among the most common diagnoses, accounting for approx. $24 \%$ thereof.

What interested authors the most in this situation was to what extent the pandemic-related job insecurity contributed to reduced psychological well-being, characterized by such phenomena as anxiety, depression, irritation or strain-related psychosomatic complaints.
In this analysis, authors relied on the tripartite model by Clark and Watson [10], which suggests the existence of a common general (nonspecific) distress construct, and implies that depression and anxiety reflect some level of mixed symptomatology. Symptoms of depression and anxiety should be divided into three factors: depression, anxiety and symptoms that are commonly experienced by both depressed and anxious individuals - distress and irritability.

Depression is best expressed by anhedonia, by low levels, or absence of, positive affect, low mood, low self-esteem and poor outlook for the future, i.e., hopelessness. It is also expressed by a lack of interest and inactivity, so employees with depression need to reduce their workload and are less productive at work. Furthermore, individuals with anxiety disorders are less likely to engage in their work. They have symptoms of somatic tension, physiological hyperarousal, specific (situational) anxiety and they experience anxious arousal. Stress is characterized by persistent tension, irritability, agitation, a low threshold for becoming upset or frustrated, and difficulty to relax [11].

Authors conducted their study in Poland in the first months of the pandemic. The research began immediately after the initial shock had subsided, as people were awaiting the implementation of policies meant to protect the labor market (the so-called anti-crisis shield) and anticipating an economic slump or a serious economic crisis. Authors were interested in the experiences of employees in times of pandemic - whether they felt anxious about their jobs and the employment insatiability, and how that related to reduced psychological well-being. In addition, authors looked to examine if this effect stemmed from the fear of losing the source of income or if another insecurity was at play here - one relating to worsening working conditions.

\section{Job and employment insecurity}

Job insecurity is an important source of stress at work. Even before the pandemic, the European Agency for Health at Work (EU-OSHA) carried out an opinion survey, which concluded that job insecurity was one of the main causes of work-related stress (next to excessive workload and poor relationships in the workplace). As many as 7 in 10 employees participating in the survey agreed with the above statement.

Anxiety arises from fear that job can be lost at any time and that finding new employment would be challenging. The pandemic could only have made these concerns more acute due to the co-existing threat to health and 
life, as well as the difficult situation on the labor market businesses tended to put recruitment of new employees on hold. The most anxiety would have been experienced by employees under short-term civil-law contracts (referred to by workers unions as 'junk' contracts).

Job insecurity is therefore a subjectively experienced anticipation of an important, undesirable event related to the work performed. This phenomenon is related to the employees' negative reactions towards changes in the context of their work. It reflects the anxiety accompanying serious and undesirable organizational changes which threaten their job stability [12].

Hellgren et al. [13] distinguished between quantitative insecurity (estimated probability of being laid off or forced into early retirement within the next year) and qualitative insecurity, relating to the prediction of qualitative worsening of various aspects of work. It is not related to the anxiety associated with keeping a job, but to concerns about worsening working conditions (e.g., pay cuts, work overload, lack of development opportunities) and the character of the work performed (e.g., the requirement to learn new skills). In the last quarter of the century, researchers have paid a lot of attention to quantitative insecurity, while qualitative insecurity has remained understudied [14].

What's characteristic about job insecurity is the fact that it's a subjective phenomenon based on how people see their working situation and how they interpret the events associated with it. The level of anxiety is influenced by the employee's conviction that he/she possesses advantageous skills, which would allow him to find a new job if need be (subjectively perceived employability).

What needs emphasizing is that predictions about a stressful event are as important, if not more important, a source of anxiety as the event itself. Some researchers point out that a prolonged state of perceived threat can lead to serious consequences, comparable even to the consequences of losing a job [15]. For this reason, the alarming labor market prognosis circulating in the media at the beginning of the pandemic, and the extended periods where mothers were forced to stay at home due to the closures of educational and care institutions, could have increased the employees' anxieties about the future and the stability of their job.

\section{Consequences of employment and job insecurity}

In these circumstances, employees suffer from a state of powerlessness, a lack of a sense of control and lack of capacity to deal with threating situations. The perceived employment insecurity is a strong stressor, which causes an aggravation of psychosomatic symptoms (such as chronic headaches, sleeping problems) and leads to a deterioration of psychological well-being in employees. The stress level rises proportionally to the level of employment insecurity. Rising stress level is characterized by such phenomena as anxiety, depression, irritation, alcohol abuse, problems with concentration, negative thoughts [16-18].

\section{MATERIAL AND METHODS}

\section{Purpose of the study}

The aim of the study was to measure the level of job insecurity (quantitative, qualitative) and the accompanying psychological consequences in the form of reduced psychological well-being: depression, anxiety and emotional stress. Authors were also interested whether the perceived employability would be a significant moderator of these relationships. Authors assumed that even in the event of high job insecurity, reduced well-being will occur mainly in a situation where employees see no chance of finding a new job.

\section{Hypothesis}

Job insecurity (quantitative and qualitative) will translate into reduced well-being (depression, anxiety and stress). The higher the job insecurity, the worse the emotional state. Authors assumed that mood disorders experienced during a pandemic can be partially explained by variables contributing to job insecurity (such as assessed job loss risk, fear of deterioration in working and employment conditions), and that the assessment of the chances of finding a new job in the event of job loss is a significant moderator of this relationship.

\section{Measurement}

To assess the level of job insecurity, authors used a questionnaire developed for the purpose of the study. When developing it, they relied partly on O'Neil and Sevastos' proposal $[19,20]$. It contained 3 subscales: Employment Uncertainty - 5 items (e.g., "I am still worried that in the current situation I may lose my job"), Job Uncertainty - 4 items (e.g., "I regret that it is impossible to return to the conditions that prevailed in my work before the onset of a pandemic") and Perceived Employment, which refers to the assessment of the likelihood of finding a new job during the crisis - 5 items (e.g., "I am afraid that if I lost my job, I would have serious problems with finding a new job in a pandemic situation" - inverted 
position). The respondents answered on a 4-point scale, where 0 - didn't apply to me at all, and 4 - it applied to me very much, or most of the time. This tool is reliable authors obtained a Cronbach's a for internal consistency for subscales of at least 0.72 .

To measure negative emotional states, authors used the DASS-21 (Depression, Anxiety and Stress Scales) by Lovibond and Lovibond [11], which is one of the most widely used tools in the world to measure affective symptoms. Authors used Polish adaptation of the questionnaire carried out by Zawislak et al. [21]. The tool consists of 21 items making up 3 subscales and measures distress along 3 axes of depression, anxiety (symptoms of psychological arousal) and stress (the more cognitive, subjective symptoms of anxiety). The Depression scale is about the perceived loss of self-esteem, motivation and interest (e.g., "I found it difficult to work up the initiative to do things"). The Anxiety scale refers to general autonomic arousal and perceived anxiety (e.g., "I felt I was close to panic"). The Emotional stress scale concerns the perceived tension, nervousness and irritability (e.g., "I found it difficult to relax"). The respondents answered on a scale from 0 - never to 3 almost always, indicating to what extent the given statement applied to them during the last week. The authors of the instrument reported that the scales had adequate psychometric properties (convergent and discriminatory validity). In authors' research the DASS-21 has revealed an internal consistency between 0.88 to 0.90 , and a reliability for total scale of 0.95 .

\section{Participants}

In the study took part 382 people. After the removal of outliers, 365 subjects aged 19-67 years $(\mathrm{M}=31.82$, $\mathrm{SD}=11.45$ ) remained in the sample, of which $69.5 \%$ were women and $30.05 \%$ men. The work experience of the respondents ranged $1-44$ years $(\mathrm{M}=11.2, \mathrm{SD}=10.76)$, $72 \%$ of respondents had dependent children. People with a loan accounted for $69 \%$ of the group. Most of the respondents worked in the private sector (83.5\%), while $16.5 \%$ worked in the state sector. The form in which the respondents were employed varied. Most people had indefinite duration contracts $(45.7 \%)$, followed by those with contracts for a definite period $(25.8 \%)$, and those working on commission contracts $(22.5 \%)$. Some of the respondents ran their own business (2.6\%) and $3.3 \%$ of the respondents declared that they work without any formal contract. When selecting respondents for the sample, authors tried to take into account the employment structure in Poland. The respondents have worked in all major sectors of the economy (trade, manufacturing, transport, construction, administration, financial institutions, healthcare), including those most affected by restrictions (hospitality, catering, services, tourism).

\section{Data analysis}

Statistical analysis was performed using SPSS. The $95 \%$ confidence interval was used. A regression analysis model was used for data analysis, expanded with moderation analysis using PROCESS macro for SPSS developed by Hayes (the number of random bootstrap samples was 10 000). Predicting the outcome variables were negative emotional states (depression, anxiety and stress) while predictor variables were job insecurity (quantitative and qualitative). The moderating variable was subjectively perceived employability.

\section{RESULTS}

The results of the DASS can give authors an assessment of emotional disturbance. Emotional syndromes such as depression, anxiety and stress vary along a continuum of severity relative to the population. Every 5 th respondent experienced considerable (at least moderate) symptoms, and was at a high risk of further problems (severe and extremely severe scores were obtained $11.2 \%$ of respondents for depression, $10.6 \%$ for anxiety and 9,1\% for stress). In this context, authors were particularly interested in the extent to which the pandemic-related job insecurity contributed to the deterioration of workers' well-being. To test the hypothesis that the emotional problems are a function of job insecurity, and, more specifically, whether perceived chance of finding a new job moderates the relationship between perceived risk of job loss or fear of deterioration in working and emotional problems, a hierarchical multiple regression analysis was conducted. Authors tested 4 models.

Model I: Depression is the predicting variable; quantitative insecurity is the predictor variable; employability is the moderator. Model I is statistically significant $\mathrm{p}<0.0001, \mathrm{~F}(3.306)=12.83$ and explains $11 \%$ of the variance of the depression variable. Quantitative insecurity significantly explains the occurrence of depressive symptoms $\beta=3.3, p=0.008$. Adding the moderator statistically doesn't improve the explanation of depressive symptoms. The impact of the moderator is insignificant $\mathrm{p}=0.09$ (Table 1$)$.

Model II: Depression is the predicting variable; qualitative insecurity is the predictor variable while 
Table 1. Predicting depression from quantitative and qualitative job insecurity and employability $(\mathrm{N}=382)$, study conducted in April-May 2020 in Poland

\begin{tabular}{|c|c|c|c|c|c|}
\hline Variable & $\beta$ & SE & $\mathrm{t}$ & $\mathrm{p}$ & $95 \% \mathrm{CI}$ \\
\hline employability & 0.65 & 1.26 & 0.51 & 0.607 & $-1.83-3.14$ \\
\hline interaction & -0.86 & 0.50 & -1.71 & 0.088 & $-1.85-0.13$ \\
\hline Qualitative job insecurity & 4.34 & 1.33 & 3.28 & 0.001 & $1.73-6.95$ \\
\hline
\end{tabular}

a)

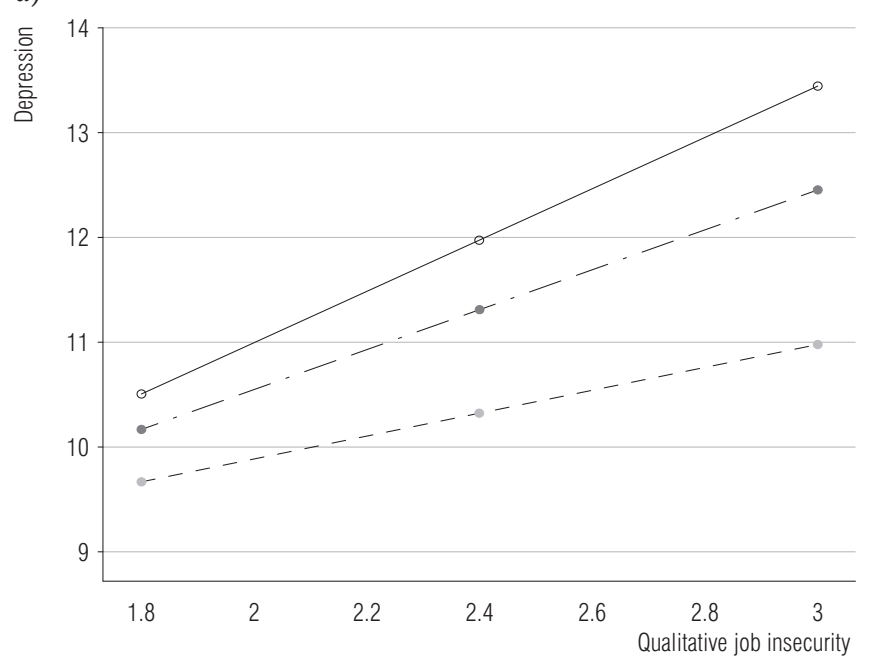

Employability:

- low - average - high - interpolation line b)

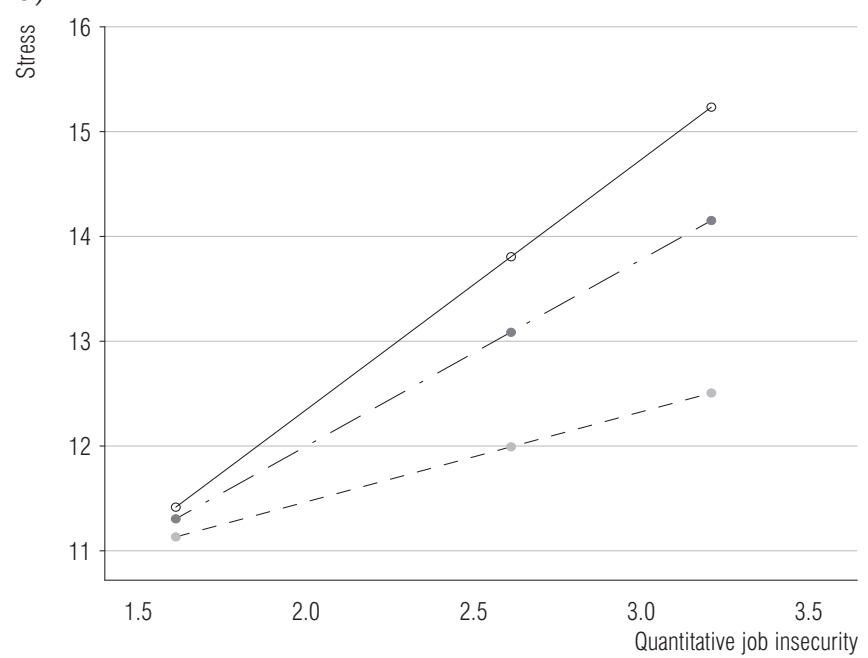

Employability:

- low - average • high ${ }^{\star} \_$interpolation line

${ }^{*}$ Not significant prediction of stress by quantitative job insecurity.

Quantitative insecurity explains the occurrence of stress, but only to a certain level of employability. When employability reaches the level of 2.98 , insecurity no longer has the explanatory power for stress.

Figure 1. Employability as a moderator between job insecurity and psychological well-being: a) employability as a moderator between qualitative job insecurity and depression, b) employability as a moderator between quantitative job insecurity and stress

employability is the moderator. Model II is statistically significant $\mathrm{p}<0.0001, \mathrm{~F}(3.306)=16.7$ and explains $14 \%$ of the variance of the depression variable. Qualitative insecurity significantly explains the occurrence of depressive symptoms $\beta=4.34, \mathrm{p}=0.0012$. Moreover, there is a statistically significant $\mathrm{p}=0.046 \mathrm{impact}$ of the moderator $\beta=-1.08, \mathrm{SE}=0.54$. Adding the moderator improves the explanation of depressive symptoms by $1.1 \%$ (Table 1). The interaction is depicted in Figure 1a.

The employability variable moderates the explanation of the occurrence of depressive symptoms via qualitative job insecurity. As shown in Figure 1a, as the level of employability increased, the strength of the relationship between qualitative job insecurity and depression decreased. Moderating the explanation of the occurrence of depressive symptoms via job insecurity is significant for each of the three identified employability groups (Table 2).

Job insecurity, both quantitative and qualitative, and the employability moderator do not explain the occurrence of the symptoms of anxiety.

In the next step, authors examined Model III, where the stress was the predicting variable, quantitative job insecurity was the predictor variable, while employability was the moderator. Model III is statistically significant $\mathrm{p}<0.0001, \mathrm{~F}(3.307)=16.45$ and explains $13.8 \%$ of the variance of the perceived stress variable. Quantitative insecurity significantly explains the occurrence of the symptoms of stress $\beta=4.52, \mathrm{SE}=1.23, \mathrm{p}=0.001$ (Table 3).

What's more, there is a statistically significant impact of the employability moderator $\mathrm{p}=0.015$, $\beta=-1.22, \mathrm{SE}=0.5$. Adding employability improves 
Table 2. Quantitative moderator between job insecurity and depression and stress $(\mathrm{N}=382)$, study conducted in April-May 2020 in Poland

\begin{tabular}{|c|c|c|c|c|c|}
\hline Employability groups & $\beta$ & SE & $\mathrm{t}$ & $\mathrm{p}$ & $95 \% \mathrm{CI}$ \\
\hline \multicolumn{6}{|l|}{ Qualitative job insecurity and depression } \\
\hline 16th percentile (1.75) & 2.45 & 0.49 & 4.96 & 0.000 & $1.48-3.42$ \\
\hline 50th percentile (2.25) & 1.91 & 0.37 & 5.12 & 0.000 & $1.17-2.64$ \\
\hline 84th percentile (3.0) & 1.10 & 0.50 & 2.17 & 0.031 & $0.10-2.09$ \\
\hline \multicolumn{6}{|l|}{ Quantitative job insecurity and stress } \\
\hline 16th percentile (low) & 2.39 & 0.46 & 5.22 & 0.0001 & $1.49-3.29$ \\
\hline 50th percentile (average) & 1.78 & 0.34 & 5.21 & 0.0001 & $1.11-2.46$ \\
\hline 84th percentile (high) & 0.87 & 0.46 & 1.89 & 0.0595 & $-0.04-1.77$ \\
\hline
\end{tabular}

Table 3. Predicting stress from job insecurity and employability $(\mathrm{N}=382)$, study conducted in April-May 2020 in Poland

\begin{tabular}{lccccc}
\hline \multicolumn{1}{c}{ Variable } & $\beta$ & $\mathrm{SE}$ & $\mathrm{t}$ & $\mathrm{p}$ & $95 \% \mathrm{CI}$ \\
\hline Quantitative job insecurity & 4.52 & 1.23 & 3.68 & 0.001 & $2.11-6.94$ \\
employability & 1.72 & 1.26 & 1.37 & 0.171 & $-0.75-4.19$ \\
interaction & -1.22 & 0.50 & -2.45 & 0.015 & $-2.20-(-0.24)$ \\
Qualitative job insecurity & 4.30 & 1.31 & 3.29 & 0.001 & $1.73-6.87$ \\
employability & 0.92 & 1.32 & 0.69 & 0.489 & $-1.69-3.52$ \\
interaction & -0.82 & 0.53 & -1.54 & 0.124 & $-1.87-0.23$ \\
\end{tabular}

the explanation of the occurrence of stress: $\Delta \mathrm{R}^{2}=1.7 \%$. As employability rises, the explanation of stress via job insecurity drops. When the intensity of employability is low, the explanation of stress via job insecurity is higher. Together with an increase in the intensity of employability, the explanation of stress via job insecurity declines. When employability reaches the score of 2.98 or higher, (Johnson-Neyman's test), quantitative insecurity no longer explains stress (Table 2). Employability buffers the explanation of stress via quantitative job insecurity. The interaction is depicted in Figure $1 b$.

In the next step Model IV was examined, where the level of stress was the predicting variable, qualitative job insecurity was the predictor variable, while employability was the moderator. Model IV is statistically significant $\mathrm{p}<0.0001, \mathrm{~F}(3.307)=21.9$ and explains $17.6 \%$ of variance of the perceived stress variable. Qualitative insecurity significantly explains the occurrence of depressive symptoms $\beta=4.30, \mathrm{p}=0.001$. The impact of employability is not significant $\mathrm{p}=0.12$ (Table 3 ).

In this study, authors also took into account the factors that may explain the effects of job insecurity on health, that may be related to the micro-environment of the individuals. Having children turned out not to be important from the point of view of both job insecurity and their mental state. On the other hand, having a significant amount of credit differentiated only the level of depression $(Z=-2.16, p=0.03)$, with depression being lower in people with credit. These results are not surprising, however, due to the pro-family policy of the Polish government in recent years (significant from the point of view of household budgets, allowances for each child). On the other hand, banks grant decisions on granting loans based on creditworthiness, e.g., a certain source of income and the amount of earnings, therefore the respondents who had a loan initially could be in a better financial condition and could be employed on more favorable terms of an employment contract. These observations were consistent with a 2010 study of 16 European countries by László et al. [22] who noted that the association between job insecurity and health did not differ significantly by age, sex, education, and marital status. Previous studies investigating gender differences in the health consequences of job insecurity have yielded conflicting results, however authors' study showed significant differences to the disadvantage of women.

\section{DISCUSSION}

The experiences of the surveyed employees during the pandemic may give rise to a concern. The results of this research showed that every tenth respondent 
experiences symptoms of reduced psychological well-being, characterized by such phenomena as anxiety, depression, irritation or strain-related psychosomatic complaints on a serious and extremely serious level. The aim of this research was to determine to what extent these negative emotional states experienced during a pandemic can be explained by variables contributing to job insecurity, such as the assessed risk of losing a job (quantitative job insecurity) and concerns about the deterioration in working and employment conditions (qualitative job insecurity).

Authors assumed that mood disorders experienced during a pandemic can be partially explained by variables contributing to job insecurity, and that the assessment of the chances of finding a new job in the event of a job loss is a significant moderator of this relationship.

The results of this analysis showed that anxiety about losing a job significantly explains the variance of depression (11\%) and stress (13.8\%). However, it did not turn out to be a significant predictor of anxiety. During the pandemic, the experienced anxiety may have resulted from a sense of threat to life and health of the respondents and their relatives, as well as from great uncertainty about the future (at the time of the study, the coronavirus vaccine development was still at a very early stage). Anxiety related to significant deterioration of working conditions (e.g., the surveyed employees will not receive their salaries on time) had a slightly greater explanatory power - it explained $14 \%$ of the variance of depression and $17.6 \%$ of stress. However, as with job insecurity, qualitative job insecurity has not been significant in explaining anxiety. The results of the analysis also showed that adding employability as a moderator improves the explanation of depressive symptoms to a very small extent, if at all (along with the increase in employability, the impact of qualitative job insecurity on depression symptoms was smaller). Similarly, adding employability caused a slight increase of the explained variance of stress in the case of quantitative job insecurity.

\section{CONCLUSIONS}

The quantitative and, to a slightly greater extent, qualitative job insecurity, translated into the deterioration of well-being in the case of 2 emotional states: depression and stress. These variables, however, account for only a small number of the observed variation in emotional syndromes. This could be due to the fact that the risk of losing a job, despite the preliminary forecasts, turned out not to be very high, while unemployment in Poland in 2020 remained at the level of 2018 and 2019, and was generally very low (ca. 5-6\%). On the other hand, the deteriorating situation of Polish enterprises, resulting, for example, from the prolonged lockdown, could raise concerns among employees that some of the costs would be passed on to them. However, it was other experiences that proved of much greater significance for the feeling of negative emotional states in the first phase of the pandemic.

\section{Limitations of the study}

This study has several limitations. First, no conclusions about causality can be drawn due to the cross-sectional design of the study. In addition to the causal link proposed, it is also likely that those who are more sensitive to anxiety are more likely to see their job as less secure and underestimate their employability.

Moreover, authors cannot build far-reaching generalizations due to the small sample size. The ability to detect significant interactions between job insecurity, mental state and the examined demographic factors may have been limited. Also, a significantly higher percentage of women than men in the research sample could have had an impact on the results, because women are more prone to anxiety and depressed mood than men.

\section{REFERENCES}

1. Rigotti T, Yang L, Jiang Z, Newmann A, De Cuyper N, Sekiguchi T. Work-Related Psychosocial Risk Factors and Coping Resources during the COVID-19 Crisis. Appl Psy. 2021;70(1):3-15, https://doi.org/10.1111/apps.12307.

2. Wachtler B, Michalski N, Nowossadeck E, Diercke M, Wahrendorf M, Santos-Hovener C, et al. Socioeconomic inequalities and COVID-19: A review of the current international literature. J Health Mon. 2020;5(7):3-17, https:// doi.org/10.25646/7059.

3. Sinclair RR, Probst TM, Watson GP, Bazzoli A. Caught between Scylla and Charybdis: How economic stressors and occupational risk factors influence workers' occupational health reactions to COVID-19. Appl Psy. 2021;70(1):85-119, https://doi.org/10.1111/apps.12301.

4. Rudolph CW, Allan B, Clark M, Hertel G, Hirschi A, Kunze F, et al. Pandemics: Implications for research and practice in industrial and organizational psychology. Ind Organ Psychol - US. 2021;14(1-2):1-35, https://doi. org/10.1017/iop.2020.48.

5. Kossowska M, Szumowska E, Szwed P. Tolerancja w czasach niepewności. Sopot: Smak Słowa; 2018. 
6. American Psychological Association. Stress in America 2020. A national mental health crisis. Washington DC: American Psychological Association; 2020.

7. Mazza C, Ricci E, Biondi S, Colasanti M, Ferracuti S, Napoli C, et al. A nationwide survey of psychological distress among Italian people during the COVID-19 pandemic: Immediate psychological responses and associated factors. Int J Env Res Pub He. 2020;17(9):31-65, https://doi. org/10.3390/ijerph17093165.

8. Gonzalez-Sanguino C, Ausin B, Castellanos M, Saiz J, López-Gómez A, Ugidos C, et al. Mental health consequences during the initial stage of the 2020 Coronavirus pandemic (COVID-19) in Spain. Brain Behav Imun. 2020;87(7): 172-6, https://doi.org/10.1016/j.bbi.2020.05.040.

9. Goldberg DP, Lecrubier Y. Form and frequency of mental disorders across centres. In: Ustun TB, Sartorius N, editors. Mental Illness in General Health Care: An International Study. New York: John Wiley \& Sons; 1995. p. 323-34.

10. Clark LA, Watson D. Tripartite model of anxiety and depression: Psychometric evidence and taxonomic implications. J Abnorm Psych. 1991;100(3):316-36.

11. Lovibond PF, Lovibond SH. The structure of negative emotional states: comparison of the Depression Anxiety Stress Scales (DASS) with the Beck Depression and Anxiety Inventories. Beh Res Ther. 1995;33(3):335-43, https:// doi.org/10.1016/0005-7967(94)00075-u.

12. Davy JA, Kinicki AJ, Scheck CL. A test of job security's direct and mediated effects on withdrawal cognitions. J Org Behav. 1997;18(4):323-49.

13. Hellgren J, Sverke M, Isaksson K. A two-dimensional approach to job insecurity: consequences for employee attitudes and well-being. Eur J Work Organ Psy. 1999;8:179-95.

14. Brondino M, Bazzoli A, Van der Elst T, De Witte H, Pasini M. Validation and measurement invariance of the multidimensional qualitative job insecurity scale. Qal Quant. 2020;54:925-42, https://doi.org/10.1007/s11135020-00966-y.

15. Kinnunen U, Mauno S, Nätti J, Happonen M. Organizational antecedents and outcomes of job insecurity: A longitudinal study in three organizations in Finland. J Org Behav. 2000;21(4):443-59.

16. Cheng T, Huang G, Lee C, Ren X. Longitudinal effects of job insecurity on employee outcomes: The moderating role of emotional intelligence and the leader-member exchange. Asia Pac J Manag. 2012;29(3):709-28.

17. Dekker S, Schaufeli W. The effects of job insecurity on psychological health and withdrawal: A longitudinal study. Aust Psychol. 1995;30(1):57-63, https://doi.org/ 10.1080/00050069508259607.

18. Richter A, Näswall K, De Cuyper N, Sverke M, De Witte $\mathrm{H}$, Hellgren J. Coping with job insecurity. Career Dev Int. 2013;18(5):484-502, https://doi.org/10.1108/CDI-062013-0081.

19. Chirkowska-Smolak T. Konsekwencje stresu wynikającego z braku bezpieczeństwa zatrudnienia i sposoby radzenia sobie z nim. Bezpieczeństwo Pracy. Nauka i Praktyka. 2015;10:8-11.

20. Chirkowska-Smolak T, Czumak M. Ryzyko braku relacji zawodowych. Konstrukcja Skali Niepewności Zatrudnienia w Sytuacji Pandemii. Człowiek i Społeczeństwo. 2021;1(51):145-64, https://doi.org/10.14746/cis.2021.51.8.

21. Zawislak D, Zur-Wyrozumska K, Habera M, Skrzypiec K, Pac A, Cebula G.. Evaluation of a Polish Version of the Depression Anxiety Stress Scales (DASS-21). J Neurosci Cogn Stud. 2020;4(1):1015.

22. László KD, Pikhart H, Kopp MS, Bobak M, Pajak A, Malyutina $S$, et al. Job insecurity and health: a study of 16 European countries. Soc Sci Med. 2010;70(6):867-74, https://doi.org/10.1016/j.socscimed.2009.11.022.

This work is available in Open Access model and licensed under a Creative Commons Attribution-NonCommercial 3.0 Poland License - http://creativecommons.org/licenses/by-nc/3.0/pl/deed.en. 